\title{
Relationship between sitting volleyball performance and field fitness of sitting volleyball players in Korea
}

\author{
Bogja Jeoung* \\ Department of Health Science, Gachon University, Incheon, Korea
}

The purpose of this study was to evaluate the relationship between sitting volleyball performance and the field fitness of sitting volleyball players. Forty-five elite sitting volleyball players participated in 10 field fitness tests. Additionally, the players' head coach and coach assessed their volleyball performance (receive and defense, block, attack, and serve). Data were analyzed with SPSS software version 21 by using correlation and regression analyses, and the significance level was set at $P<0.05$. The results showed that chest pass, overhand throw, onehand throw, one-hand side throw, splint, speed endurance, reaction time, and graded exercise test results had a statistically significant influence on the players' abilities to attack, serve, and block. Grip strength, $t$-test, speed, and agility showed a statistically significant relationship with the players' skill at defense and receive. Our results showed that chest pass, overhand throw, one-hand throw, one-hand side throw, speed endurance, reaction time, and graded exercise test results had a statistically significant influence on volleyball performance.

Keywords: Sitting volleyball, Field fitness, Athlete

\section{INTRODUCTION}

Scientific approaches should be used to improve athletes' performance and to select outstanding athletes and training programs for elite sports. One essential fundamental step of the scientific approach is systematic collection of empirical data of various phenomena. Previously, many sports scientists have investigated various characteristics such as physical fitness, kinanthropometry, psychology, and motor function in elite athletes (Marszalek et al., 2015; Molik et al., 2008, 2010, 2012, 2013, 2017). Elite athletes were studied because it was assumed that since they were at the top level of their sport, their physical fitness, kinanthropometry, and psychology, as well as sports performance skill, would be optimized to perform their sport in an ideal form. This approach is also applicable to sports for the disabled. It is assumed that elite sports for the disabled also require physical fitness and kinanthropometry optimized for the type and characteristics of each sport, and physical fitness is fundamental for good performance (Aouadi et al, 2012; Carter, 1987; Coleman 2002).
Regarding sports for the disabled, sitting volleyball is a fast, high-level competitive team sport, demanding power and agility. The participation of individuals who are physically disabled in elite, competitive sports is probably the most disputed part of the whole sphere of sports. Strength and athletic ability are commonly required for sports, specifically sports for disabled, including competitive sitting volleyball (Vute, 1999).

Since sitting volleyball players can receive the ball from any direction and must relay it to the next play, either with attack or defense, they need to quickly make decisions and move. In addition, they need height and power to drop the ball in the opponents' court. Stamina and physical fitness factors affect performance so that physical fitness is a fundamental factor for a high level of skill and strategic training.

Since most sitting volleyball players are disabled in their lower bodies, it is important for them to have upper body physical fitness, core muscle strength, and good balance in the sitting position (Lee and Kim, 2010). The rules of sitting volleyball specify that the team can touch the ball 3 times on its side of the net, and
${ }^{*}$ Corresponding author: Bogja Jeoung (ib https://orcid.org/0000-0002-7144-6179 Department of Health Science, Gachon University, 191 Hambangmoe-ro, Yeonsugu, Incheon 21936, Korea

Tel: +82-32-820-4766, Fax: +82-32-820-4350, E-mail: bogja05@gachon.ac.kr Received: November 4, 2017 / Accepted: December 5, 2017
This is an Open Access article distributed under the terms of the Creative Commons Attribution Non-Commercial License (http://creativecommons.org/licenses/by-nc/4.0/) which permits unrestricted non-commercial use, distribution, and reproduction in any medium, provided the original work is properly cited. 
by the third touch, the team members must try to direct the ball to the opponents' side of the court in an attempt to score a point. Players can move by using their hands and sliding on the court, but the players' actions are determined according to the position of their buttocks.

Players use their hands to move and slide across the playing court, and their buttocks must remain on the floor when playing, blocking, and serving. For official tournaments, a minimum disability is required. At least one part of the player's buttocks must remain on the floor while the ball is in play, that is, while passing (receiving, tossing), attacking, blocking, and serving. To perform volleyball skills well under these rules, a high level of physical fitness is required (Ko and Kim, 2004; Marszalek et al., 2015; Molik et al., 2017). Coaches need to take players' fitness levels into account when seeking to improve the players' training plan and game management.

Presently, currently available physical fitness tests (field fitness test/nonlaboratory test) could be used to assess sitting volleyball players' fitness levels, but there have been few studies on which field fitness factors affect sitting volleyball skills. It would be helpful for coaches to evaluate the sports performance of sitting volleyball athletes using a field test that would assess the fitness level of sitting volleyball players. The purpose of this study was to evaluate relationships between field fitness and the volleyball skill performance of sitting volleyball players.

\section{MATERIALS AND METHODS}

\section{Participants}

The participants were 45 sitting volleyball players who had participated in the Korea National volleyball game from 2016 to 2017. The players' mean age was $42.5 \pm 7.4$ (range, 27-50) years old. The legal guardians provided informed consent for the sitting volleyball players to participate in the study, and all procedures were conducted in accordance with our university's ethical standards. The participants' characteristics are shown in Table 1.

\section{Procedure}

The dates for testing were set up with the team manager or coach, and the tests were performed at the Gachon University exercise rehabilitation center.

All the important research explanations and information were provided to the team manager and each player. All participants signed an informed consent document and completed a personal questionnaire (full name, age, type of disability, sex, game posi-
Table 1. Characteristics of participants

\begin{tabular}{lcc}
\hline Variable & Mean \pm SD & Range \\
\hline Age (yr) & $42.5 \pm 7.4$ & $27-50$ \\
Weight $(\mathrm{kg})$ & $73.1 \pm 11.4$ & $50.7-89$ \\
Height $(\mathrm{cm})$ & $171.2 \pm 11.4$ & $144-184$ \\
Abdominal circumference (cm) & $91.08 \pm 7.8$ & $75.5-105$ \\
Grip strength (kg) & $44.85 \pm 6.5$ & $31.4-53.8$ \\
Shoulder back scratch (cm) & $-18.7 \pm 13.0$ & -3.0 to 52.5 \\
Speed endurance (sec) & $22.55 \pm 4.33$ & $10.81-29.28$ \\
Chest pass throw (cm) & $473.8 \pm 97.8$ & $292-675$ \\
Over hand throw (cm) & $452.5 \pm 75.0$ & $311-580$ \\
One-hand throw (cm) & $468.56 \pm 67.06$ & $361-650$ \\
One-hand side throw (cm) & $501.86 \pm 107.2$ & $270-725$ \\
Splint 3 m (sec) & $1.54 \pm .51$ & $0.72-2.78$ \\
$t$-test (sec) & $15.8 \pm 3.9$ & $11.17-24.7$ \\
Speed agility (sec) & $2.38 \pm .68$ & $1.32-3.54$ \\
GXT total time (min) & $7.42 \pm 1.13$ & $5.10-10.00$ \\
Reaction time (sec) & $13.8 \pm 1.26$ & $11.42-15.65$ \\
Volley ball performance (score) & $22.27 \pm 5.8$ & $10-32$ \\
Spike (score) & $5.45 \pm 1.9$ & $2-9$ \\
Block (score) & $5.0 \pm 1.7$ & $2-9$ \\
Serve (score) & $6.09 \pm 1.8$ & $3-10$ \\
Receive \& defense (score) & $5.72 \pm 1.8$ & $2-8$ \\
\hline SO & &
\end{tabular}

$\mathrm{SD}$, standard deviation.

tion, volleyball game career). Anthropometric measurements recorded included the vertical reach in a seated position, body height and weight, abdominal circumference, and shoulder back scratch.

We measured field fitness using a graded exercise test (GXT) with an arm ergometer. The testing protocol was to raise $50 \mathrm{~W}$ every $2 \mathrm{~min}$ while maintaining $60 \mathrm{rpm}$. The maximum heart rate was set at $80 \%$, but the test was also stopped if the player was unable to finish it or had abnormal blood pressure. Heart rate and blood pressure were measured at each stage, and the test duration was recorded. Additionally, a field fitness test proposed by Marszalek et al. (2015) including a sprint test, a t-test, speed and agility test, and speed and endurance test was performed. Additionally, all athletes performed a chest pass test, both-hand overhand throw, one-hand throw, and one-hand side throw 3 times each, and the highest score was recorded.

The next part of this study concerned volleyball performance. The coach scored and recorded each player's volleyball performance, including attack, blocking, serve, defense, and receive based on 10 points as $100 \%$.

\section{Data analysis}

Data were analyzed with IBM SPSS Statistics ver. 21.0 (IBM 
Corp., Armonk, NY, USA). Descriptive statistics were used according to the study objectives, and the Pearson analysis and the Spearman rank correlation coefficient analysis were performed to examine the relationship between volleyball performance and field fitness. A line regression was calculated on the volleyball performance subdomains that showed a significant correlation to analyze their effects on subdomains of field fitness. The level of significance was set at $P<0.05$.

\section{RESULTS}

\section{Correlations between field fitness and volleyball performance}

Table 2 showed that when the relationship between volleyball performance and field fitness was analyzed, field fitness factors that had significant correlations with attack were chest pass $(r=0.642$, $P<0.01)$, overhand throw $(r=0.79, P<0.01)$, one-hand throw $(r=0.75, P<0.01)$, one-hand side throw $(r=0.77, P<0.01)$, splint $(r=-0.40, P<0.01)$, speed endurance $(r=-0.28, P<0.05)$, reaction time $(r=-0.31, P<0.01)$, and total GXT time $(r=0.74, P<0.01)$.

Field fitness factors that had significant correlations with serve were shoulder back scratch $(r=-0.27, P<0.01)$, grip strength $(r=$ $0.24, P<0.05)$, chest pass $(r=0.52, P<0.01)$, overhand throw $(r=0.678, P<0.01)$, one-hand throw $(r=0.79, P<0.01)$, one-hand side throw $(r=0.52, P<0.01)$, splint $(r=-0.33, P<0.01)$, speed endurance $(r=-0.24, P<0.05)$, reaction time $(r=-0.24, P<0.05)$, and GXT total time $(r=0.62, P<0.01)$.

Table 2. Correlations between field fitness and volleyball performance

\begin{tabular}{llllll}
\hline Variable & Spike & Serve & Block & $\begin{array}{l}\text { Defense } \\
\text { \& receive }\end{array}$ & $\begin{array}{l}\text { Perfor- } \\
\text { mance }\end{array}$ \\
\hline Abdominal circumference & 0.076 & -0.009 & -0.106 & 0.109 & 0.024 \\
Shoulder back scratch & -0.042 & $-0.274^{* *}$ & $0.215^{*}$ & -0.038 & -0.047 \\
Grip strength & 0.155 & $0.243^{*}$ & 0.197 & $-0.233^{*}$ & 0.117 \\
Chest pass & $0.642^{* *}$ & $0.523^{* *}$ & $0.651^{* *}$ & 0.056 & $0.600^{* *}$ \\
Over hand throw & $0.793^{* *}$ & $0.678^{* *}$ & $0.703^{* *}$ & 0.139 & $0.742^{* *}$ \\
One-hand throw & $0.757^{* *}$ & $0.790^{* *}$ & $0.723^{* *}$ & 0.176 & $0.783^{* *}$ \\
One-hand side throw & $0.778^{* *}$ & $0.524^{* *}$ & $0.710^{* *}$ & 0.033 & $0.657^{* *}$ \\
Splint & $-0.408^{* *}$ & $-0.330^{* *}$ & $-0.444^{* *}$ & -0.165 & $-0.431^{* *}$ \\
t-test & -0.063 & -0.011 & -0.075 & $0.277^{* *}$ & 0.039 \\
Speed \& agility & -0.148 & -0.125 & -0.157 & $0.286^{* *}$ & -0.048 \\
Speed endurance & $-0.280^{*}$ & $-0.248^{*}$ & $-0.329^{* *}$ & 0.197 & $-0.215^{*}$ \\
Reaction time & $-0.316^{* *}$ & $-0.246^{*}$ & $-0.415^{* *}$ & -0.181 & $-0.369^{* *}$ \\
GXT total time & $0.743^{* *}$ & $0.622^{* *}$ & $0.730^{* *}$ & $0.307^{* *}$ & $0.773^{* *}$ \\
\hline
\end{tabular}

GXT, graded exercise test.

${ }^{*} P<0.05$. ${ }^{* *} P<0.01 .{ }^{* *} P<0.001$
Field fitness factors that had significant correlations with blocking were shoulder back scratch $(r=0.21, P<0.05)$, chest pass $(r=$ $0.65, P<0.01)$, overhand throw $(r=0.70, P<0.01)$, one-hand throw $(r=0.72, P<0.01)$, one-hand side throw $(r=0.71, P<0.01)$, splint $(-0.44, P<0.01)$, speed endurance $(r=-0.32, P<0.01)$, reaction time $(r=-0.41, P<0.01)$, and GXT total time $(r=0.73, P<0.01)$.

Defense and receive were significantly correlated with grip strength $(r=0.23, P<0.05), t$-test $(r=0.27, P<0.01)$, speed and agility $(r=0.27, P<0.01)$, and GXT total time $(r=0.30, P<0.01)$.

Volleyball performance was significant correlated with chest pass $(r=0.60, P<0.01)$, overhand throw $(r=0.74, P<0.01)$, onehand throw $(r=0.78, P<0.01)$, one-hand side throw $(r=0.65$, $P<0.01)$, splint $(r=-0.43, P<0.01)$, speed endurance $(r=-0.21$, $P<0.05)$, reaction time $(r=-0.36, P<0.01)$, and GXT total time $(r=0.77, P<0.01)$.

\section{Regression analysis of volleyball performance and field fitness}

\section{Regression analysis of spike and field fitness}

Table 3 shows that the chest pass score is predicted to increase by 0.46 for every 1 -point increase in the attack score. Moreover, the overhand throw is predicted to increase by 0.021 , one-hand throw by 0.022 , one-hand side throw by 0.014 , splint by -1.56 , speed endurance by -0.12 , reaction time by -0.49 , and total GXT time by 1.36 for every 1 point increase in the attack score. The coefficient of determination that explains this change is $R^{2}=0.92$.

Table 3. Regression analysis of spike and field fitness

\begin{tabular}{lccrc}
\hline Variable & $B$ & $b$ & $t$-test & $P$-value \\
\hline Shoulder back scratch & 0.019 & 0.076 & 0.706 & 0.482 \\
Grip strength & 0.046 & 0.155 & 4.453 & 0.150 \\
Chest pass & 0.031 & 0.642 & 7.775 & $0.000^{* * *}$ \\
Over hand throw & 0.021 & 0.793 & 12.054 & $0.000^{* * *}$ \\
One-hand throw & 0.022 & 0.757 & 1.740 & $0.000^{* * *}$ \\
One-hand side throw & 0.014 & 0.778 & 11.470 & $0.000^{* * *}$ \\
Splint & -1.568 & -0.408 & -4.147 & $0.000^{* * *}$ \\
$t$-test & -0.031 & -0.063 & -0.584 & 0.561 \\
Speed agility & -0.126 & -0.148 & -1.380 & 0.170 \\
Speed endurance & -0.128 & -0.280 & -2.636 & $0.010^{* *}$ \\
Reaction time & -0.491 & -0.316 & -3.085 & $0.003^{* *}$ \\
GXT total time & 1.367 & 0.743 & 9.277 & $0.000^{* * *}$ \\
$R^{2}$ & \multicolumn{5}{c}{0.925} & \\
\hline
\end{tabular}

GXT, graded exercise test.

${ }^{*} P<0.05$. ${ }^{* *} P<0.01 .{ }^{* * *} P<0.001$. 


\section{Regression analysis of serve and field fitness}

The serve score was also predicted to increase by 1 when the shoulder back scratch score decreased by -0.39 , grip strength score increased by 0.068 , chest pass score increased by 0.010 , overhand throw score increased by 0.017 , one-hand throw score increased by 0.022 , and one-hand side throw score increased by 0.009 . The coefficient of determination that explains this change is $R^{2}=0.801$ (Table 4).

\section{Regression analysis of block and field fitness}

The blocking score increased by $1\left(R^{2}=0.897\right)$ when the chest

Table 4. Regression analysis of serve and field fitness

\begin{tabular}{lcccc}
\hline Variable & $B$ & $b$ & $t$-test & $P$-value \\
\hline Shoulder back scratch & -0.039 & -0.274 & -2.640 & $0.010^{* *}$ \\
Grip strength & 0.068 & 0.243 & 2.320 & $0.022^{*}$ \\
Chest pass & 0.010 & 0.523 & 5.690 & $0.000^{* * *}$ \\
Over hand throw & 0.017 & 0.678 & 8.560 & $0.000^{* * *}$ \\
One-hand throw & 0.022 & 0.790 & 11.960 & $0.000^{* * *}$ \\
One-hand side throw & 0.009 & 0.524 & 5.712 & $0.000^{* * *}$ \\
Splint 3 m & -1.19 & -0.330 & -3.240 & $0.002^{* * *}$ \\
t-test & -0.005 & -0.011 & -0.106 & 0.916 \\
Speed agility & -0.101 & -0.125 & -1.170 & 0.245 \\
Speed endurance & 0.108 & -0.248 & -2.320 & $0.023^{*}$ \\
Reaction time & -0.359 & -0.246 & -2.355 & $0.021^{*}$ \\
GXT total time & 1.001 & 0.622 & 6.648 & $0.000^{* * *}$ \\
$R^{2}$ & \multicolumn{5}{c}{0.801} & \\
\hline
\end{tabular}

GXT, graded exercise test.

${ }^{*} P<0.05 .{ }^{* *} P<0.01 .{ }^{* *} P<0.001$.

Table 5. Regression analysis of block and field fitness

\begin{tabular}{lcccc}
\hline Variable & $B$ & $b$ & $t$-test & $P$-value \\
\hline Shoulder back scratch & -0.024 & -0.106 & -0.993 & 0.323 \\
Grip test & 0.054 & 0.197 & 1.860 & 0.066 \\
Chest pass & 0.012 & 0.651 & 7.959 & $0.000^{* * *}$ \\
Over hand throw & 0.017 & 0.703 & 9.170 & $0.000^{* * *}$ \\
One-hand throw & 0.019 & 0.723 & 9.700 & $0.000^{* * *}$ \\
One-hand side throw & 0.012 & 0.710 & 9.340 & $0.000^{* * *}$ \\
Splint & -1.56 & -0.444 & -4.600 & $0.000^{* * *}$ \\
$t$-test & -0.034 & -0.075 & -0.694 & 0.489 \\
Speed agility & -0.123 & -0.157 & -1.470 & 0.144 \\
Speed endurance & -0.139 & -0.359 & -3.155 & $0.002^{* *}$ \\
Reaction time & -0.590 & -0.415 & -4.235 & $0.000^{* * *}$ \\
GXT total time & 1.258 & 0.730 & 8.940 & $0.000^{* * *}$ \\
$R^{2}$ & \multicolumn{5}{c}{0.897} \\
\hline
\end{tabular}

GXT, graded exercise test

${ }^{*} P<0.05 .{ }^{* *} P<0.01 .{ }^{* * *} P<0.001$. pass score increased by 0.12 , overhand throw score increased by 0.017 , one-hand throw score increased by 0.019 , one-hand side throw score increased by 0.012 , splint score decreased by -1.56 , speed endurance score decreased by -0.139 , reaction time score decreased by -0.590 , and total GXT time increased by 1.25 . The coefficient of determination that explains this change is $R^{2}=0.897$ (Table 5).

\section{Regression analysis of receive and defense and field fitness}

The receive and defense score increased by $1\left(R^{2}=0.470\right)$ as the grip strength score increased by $0.65, t$-test score decreased by

Table 6. Regression analysis of receive and defense and field fitness

\begin{tabular}{lcccc}
\hline Variable & $B$ & $b$ & $t$-test & $P$-value \\
\hline Shoulder back scratch & -0.005 & -0.038 & -0.352 & 0.726 \\
Grip test & 0.065 & 0.233 & 2.222 & $0.029^{*}$ \\
Chest pass & 0.001 & 0.056 & 0.516 & 0.607 \\
Over hand throw & 0.003 & 0.139 & 1.29 & 0.198 \\
One-hand throw & 0.005 & 0.176 & 1.60 & 0.101 \\
One-hand side throw & 0.001 & 0.033 & 0.309 & 0.758 \\
Splint 3 m & -0.590 & -0.165 & -1.55 & 0.124 \\
$t$-test & -0.129 & -0.277 & -2.67 & $0.009^{* *}$ \\
Speed agility & -0.228 & -0.286 & 2.76 & $0.007^{* *}$ \\
Speed endurance & -0.083 & -0.197 & 1.82 & 0.072 \\
Reaction time & -0.262 & -0.181 & -1.70 & 0.091 \\
GXT total time & 0.515 & 0.307 & 2.69 & $0.009^{* *}$ \\
$R^{2}$ & \multicolumn{5}{c}{0.470} \\
\end{tabular}

GXT, graded exercise test.

${ }^{*} P<0.05 .{ }^{* *} P<0.01 .{ }^{* * *} P<0.001$.

Table 7. Regression analysis of volleyball performance and field fitness

\begin{tabular}{lcccc}
\hline Variable & $B$ & $b$ & $t$-test & $P$-value \\
\hline Shoulder back scratch & -0.021 & -0.047 & -0.434 & 0.665 \\
Grip test & 0.104 & 0.117 & 1.09 & 0.278 \\
Chest pass & 0.036 & 0.600 & 6.96 & $0.000^{* * *}$ \\
Over hand throw & 0.058 & 0.742 & 10.27 & $0.000^{* * *}$ \\
One-hand throw & 0.068 & 0.783 & 11.68 & $0.000^{* * *}$ \\
One-hand side throw & 0.036 & 0.657 & 8.089 & $0.000^{* * *}$ \\
Splint & -4.91 & -0.431 & -4.428 & $0.000^{* * *}$ \\
$t$-test & 0.058 & 0.039 & 0.362 & 0.718 \\
Speed agility & -0.123 & -0.048 & -0.448 & 0.656 \\
Speed endurance & -0.292 & -0.215 & -1.99 & $0.050^{*}$ \\
Reaction time & -1.70 & -0.369 & -3.68 & $0.000^{* * *}$ \\
GXT total time & 4.41 & 0.773 & 10.20 & $0.000^{* * *}$ \\
$R^{2}$ & & & 0.825 &
\end{tabular}

GXT, graded exercise test.

${ }^{*} P<0.05 .{ }^{* *} P<0.01 .{ }^{* *} P<0.001$. 
0.017 , speed and agility score decreased by -0.228 , and total GXT time increased by 0.515 . The coefficient of determination that explains this change is $R^{2}=0.470$ (Table 6).

\section{Volleyball performance and field fitness}

Table 7 shows that the volleyball performance score is predicted to increase by 1 as chest pass score increases by 0.36 , overhand throw score increases by 0.058 , one-hand throw score increases by 0.068 , one-hand side throw score increases by 0.036 , splint score decreases by -4.91 , speed endurance score decreases by -0.292 , reaction time score decreases by -1.70 , and total GXT time increases by 4.41 . The coefficient of determination that explains this change is $R^{2}=0.825$.

\section{DISCUSSION}

The purpose of this study was to evaluate the relationship between the performance of sitting volleyball skills and the field fitness of sitting volleyball players. The result of this study confirmed the relationship between spike and chest pass, overhand throw, one-hand throw, one-hand side throw, splint, speed endurance, reaction time, and total GXT time. Moreover, serve correlated with shoulder back scratch, grip strength, chest pass, overhand throw, one-hand throw, one-hand side throw, splint, speed endurance, reaction time, and total GXT time. Blocking was correlated with shoulder back scratch, chest pass, overhand throw, one-hand throw, one-hand side throw, splint, speed endurance, reaction time, and total GXT time. There was a relationship between defense and receive and grip strength, $t$-test, speed and agility, and total GXT time. Volleyball performance was correlated with chest pass, overhand throw, one-hand throw, one-hand side throw, splint, speed endurance, reaction time, and total GXT time.

These selected field fitness factors could be a tool for coaches to evaluate attack and serve and can also be used as a predictive assessment tool to improve blocking skill. In a preceding study, Marszalek et al. (2015) reported that block and spike had correlations with splint, chest pass, $t$-test, and speed agility and were influencing factors for them. In contrast, the present study found that spike and block had no relationship with $t$-test and speed and agility, showing contradictory results with the preceding study. In particular, Marszalek et al. (2015) reported that the $t$-test affected block and spike, whereas the present study found that the $t$-test was a field fitness factor associated with improved defense and receive. In addition, speed and endurance test factors had no effect on the performance of volleyball skills in the preceding study, where- as they affected defense and receive in our study.

In an evaluation of game performance of male sitting volleyball players, Molik et al. (2017) reported that there was a relationship between vertical reach in the seated position and volleyball game performance, and they reported that vertical reach in the seated position is one of the most crucial factors in the volleyball performance of athletes. However, the present study did not measure vertical reach in the seated position. Thus, further study is needed on the relationship between vertical reach in the seated position and volleyball performance.

Souto et al. (2015) reported that agility is important for sitting volleyball performance, and Molik et al. (2008, 2013) also reported that splint test and chest pass are important physical fitness factors for sitting volleyball players.

Judging by the results of preceding studies and the present study, it seems obvious that chest pass, overhand throw, one-hand throw, and one-hand side throw test using a medicine ball are test items that measure power strength with simultaneous coordination of the upper body (shoulder, arm, wrist, etc.), abdomen, and waist. For a better performance of spike and serve, the shoulder, arm, and waist should also exert power simultaneously in coordination. Because of these common characteristics, throwing a medicine ball in a field fitness test is correlated with the effectiveness of spike and serve. This test could be a good tool to assess a player's performance.

In order to perform an overall assessment of sitting volleyball players, a coach also needs to evaluate the game performance. The lack of those analyses in the present study is one of its limitations.

Based on our results, we drew the following conclusions: optimal performance of the field fitness test items of attack, serve, and block in volleyball performance is dependent on chest pass, overhand throw, one-hand throw, splint, speed endurance, reaction time, and GXT. Meanwhile, optimal performance of defense and receive are dependent on grip strength, $t$-test, speed and agility, and GXT test. Therefore, it is expected that these results would be useful for volleyball coaches or leaders in planning physical fitness training to improve field fitness in the volleyball field. There is a need to continue research on the relationship between field fitness tests and practical game performance.

\section{CONFLICT OF INTEREST}

No potential conflict of interest relevant to this article was reported. 


\section{REFERENCES}

Aouadi R, Jlid MC, Khalifa R, Hermassi S, Chelly MS, Van Den Tillaar R, Gabbett T. Association of anthropometric qualities with vertical jump performance in elite male volleyball players. J Sports Med Phys Fitness 2012;52:11-17.

Carter JE. Physical structure of Olympic athletes. Part II: Kinanthropometry of Olympic athletes. Basel (Switzerland): Karger; 1987. (Medici and Sport Science; v. 18).

Coleman J. Scouting opponents and evaluating team performance. In: Shondell DS, Reynaud C, editors. The volleyball coaching bible. Champaign (IL): Human Kinetics; 2002. p. 321-346.

Ko BG, Kim JH. Physical fitness profiles of elite ball game athletes. Int J Appl Sports Sci 2005;17:71-87.

Lee YA, Kim HC. Application of intensified program to increase physical fitness, mobility and confidence on specific sports among volleyball sitting athletes. Korean Phys Mult Disabil 2010;53:89-109.

Marszalek J, Molik, Gomez MA, Skučas K, Lencse-Mucha J, Rekowski W, Pokvytyte V, Rutkowska I, Kaźmierska-Kowalewska K. Relationship between anaerobic performance, field tests and game performance of sitting volleyball players. J Hum Kinet 2015;48:25-32.

Molik B, Kosmol A, Skucas K. Sport - specific and general sporting phys- ical fitness of sitting volleyball. Physiotherapy 2008;16:68-75.

Molik B, Laskin JJ, Kosmol A, Marszałek J, Morgulec-Adamowicz N, Frick T. Relationships between anaerobic performance, field tests, and functional level of elite female wheelchair basketball athletes. Hum Mov 2013;14:366-371.

Molik B, Laskin JJ, Kosmol A, Skucas K, Bida U. Relationship between functional classification levels and anaerobic performance of wheelchair basketball athletes. Res Q Exerc Sport 2010;81:69-73.

Molik B, Morgulec-Adamowicz N, Kosmol A, Yilla AB, Filipkowska A, Lewandowski M, Pijanowska J, Słyk K, Zubala T, Flis S, Herink R. Game performance in ice sledge hockey: an exploratory examination into type of disability and anthropometric parameters. Clin J Sport Med 2012;22:65-69.

Molik B, Morgulec-Adamowicz N, Marszałek J, Kosmol A, Rutkowska I, Jakubicka A, Kaliszewska E, Kozłowski R, Kurowska M, Ploch E, Mustafins P, Gómez MÁ. Evaluation of game performance in elite male sitting volleyball players. Adapt Phys Activ Q 2017;34:104-124.

Souto EC, Oliveira LD, Neto AM, Greguol M. Scientific authenticity of an agility test for the sitting volleyball. Motricidade 2015;11:82-91.

Vute R. Scoring skills performances of the top international men's sitting volleyball teams. Gymnica 1999;29:55-62. 